\title{
Pulmonary metastasectomy with therapeutic intent for soft-tissue sarcoma
}

\author{
Neel P. Chudgar, MD, ${ }^{\text {a }}$ Murray F. Brennan, MD, ${ }^{\text {a }}$ Rodrigo R. Munhoz, MD, ${ }^{b}$ Peter R. Bucciarelli, MD, ${ }^{a}$ \\ Kay See Tan, PhD, ${ }^{c}$ Sandra P. D'Angelo, MD, ${ }^{b}$ Manjit S. Bains, MD, ${ }^{a}$ Matthew Bott, MD, ${ }^{a}$ \\ James Huang, MD, ${ }^{a}$ Bernard J. Park, MD, ${ }^{a}$ Valerie W. Rusch, MD, ${ }^{a}$ Prasad S. Adusumilli, MD, ${ }^{a}$ \\ William D. Tap, MD, ${ }^{\mathrm{b}}$ Samuel Singer, MD, ${ }^{\mathrm{a}}$ and David R. Jones, $\mathrm{MD}^{\mathrm{a}}$
}

\section{ABSTRACT}

Objective: Soft-tissue sarcoma is a heterogeneous disease that frequently includes the development of pulmonary metastases. The purpose of this study is to determine factors associated with improved survival among patients with soft-tissue sarcoma to help guide selection for pulmonary metastasectomy.

Methods: We reviewed a prospectively maintained database and identified 803 patients who underwent pulmonary metastasectomy for metastatic soft-tissue sarcoma between September 1991 and June 2014; of these, 539 patients undergoing 760 therapeutic-intent pulmonary metastasectomies were included. Clinicopathologic variables and characteristics of treatment were examined. The outcomes of interest were overall survival and disease-free survival. Survival was estimated with the Kaplan-Meier method and compared between variables with the log-rank test. Factors associated with hazard of death and recurrence were identified via the use of univariable and multivariable Cox proportional hazards models.

Results: Median overall survival was 33.2 months (95\% confidence interval, 29.9-37.1), and median disease-free survival was 6.8 months (95\% confidence interval, 6.0-8.0). In multivariable analyses, leiomyosarcoma histologic subtype $(P=.007)$, primary tumor size $\leq 10 \mathrm{~cm}(P=.006)$, increasing time from primary tumor resection to development of metastases $(P<.001)$, solitary lung metastasis $(P=.001)$, and minimally invasive resection $(P=.023)$ were associated with lower hazard of death. Disease-free interval $\geq 1$ year $(P=.002)$, and 1 pulmonary metastasis $(P<.001)$ were associated with lower hazard of disease recurrence.

Conclusions: In a large single-institution study, primary tumor histologic subtype and size, numbers of pulmonary metastases, disease-free interval, and selection for minimally invasive resection are associated with increased survival in patients undergoing pulmonary metastasectomy for soft-tissue sarcoma. (J Thorac Cardiovasc Surg 2017;154:319-30)

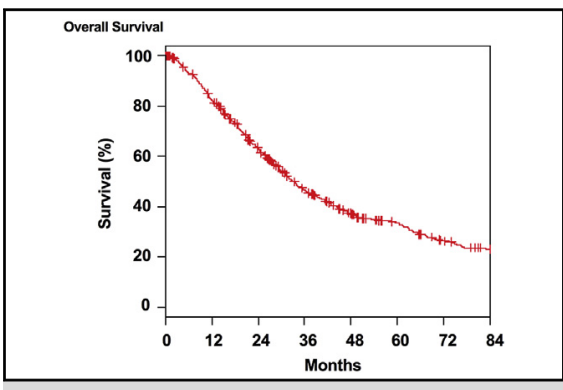

The median overall survival for patients undergoing pulmonary metastasectomy for soft-tissue sarcoma was 33.2 months, with a 5 -year survival of $34 \%$.

\section{Central Message}

Tumor subtype and size, number of and time to metastases, and minimally invasive surgery were associated with longer survival in patients with sarcomatous pulmonary metastases.

\section{Perspective}

Up to $50 \%$ of patients with soft tissue sarcoma develop pulmonary metastases. Effective systemic therapies for metastatic soft-tissue sarcoma currently are limited; when possible, pulmonary metastasectomy is the preferred treatment modality. Guidelines for the performance of pulmonary metastasectomy for soft-tissue sarcoma do not exist, and decisions to operate are often made on an individual basis. We report prognostic factors to assist operative selection for these patients.

See Editorial Commentary page 331.

See Editorial page 317.

\footnotetext{
From the Departments of ${ }^{a}$ Surgery, ${ }^{b}$ Medical Oncology, and ${ }^{c}$ Epidemiology and Biostatistics, Memorial Sloan Kettering Cancer Center, New York, NY.

Supported by grants R01 CA136705 (to Dr Jones), U54 CA137788 (to Dr Adusumilli), and 5 T32 CA 9501-27 (Dr Bucciarelli) from the National Institutes of Health/National Cancer Institute (NIH/NCI). This work also was supported, in part, by NIH/NCI Cancer Center Support Grant P30 CA008748.

Read at the 96th Annual Meeting of The American Association for Thoracic Surgery, May 14-18, 2016, Baltimore, Maryland.

Received for publication April 26, 2016; revisions received Feb 7, 2017; accepted for publication Feb 21, 2017; available ahead of print April 8, 2017.

Address for reprints: David R. Jones, MD, Thoracic Surgery Service, Department of Surgery, 1275 York Ave, Box 7, Memorial Sloan Kettering Cancer Center, New York, NY 10065 (E-mail: jonesd2@mskcc.org).

$0022-5223 / \$ 36.00$

Copyright (C) 2017 by The American Association for Thoracic Surgery http://dx.doi.org/10.1016/j.jtcvs.2017.02.061
}

Although soft-tissue sarcoma (STS) is considered an uncommon disease, its incidence has nearly doubled during the last 2 decades. Approximately 12,000 new cases are diagnosed in the United States annually, with nearly 5000 deaths. ${ }^{1}$ Adding to the difficulty in studying and treating

Scanning this QR code will take you to supplemental tables and a figure. To view the AATS 2016 Webcast, see the URL next to the video thumbnail. 


$$
\begin{aligned}
& \text { Abbreviations and Acronyms } \\
& \begin{aligned}
\text { CI } & =\text { confidence interval } \\
\text { DFI } & =\text { disease-free interval } \\
\text { DFS } & =\text { disease-free survival } \\
\text { HR } & =\text { hazard ratio } \\
\text { MIS } & =\text { minimally invasive surgery } \\
\text { MFH } & =\text { malignant fibrous histiocytoma } \\
\text { MSKCC } & =\text { Memorial Sloan Kettering Cancer } \\
& \text { Center } \\
\text { OS } & =\text { overall survival } \\
\text { PM } & =\text { pulmonary metastasectomy } \\
\text { PS } & =\text { pleomorphic sarcoma } \\
\text { STS } & =\text { soft-tissue sarcoma }
\end{aligned}
\end{aligned}
$$

this relatively uncommon disease, sarcoma represents a heterogeneous spectrum, with at least 80 subtypes identified. $^{2}$

Pulmonary metastases develop in up to $50 \%$ of patients with STS. ${ }^{3-7}$ Sarcomas disseminate hematogenously, with lymphatic metastases (which are associated with predominately epithelioid subtypes) occurring infrequently. ${ }^{2,8}$ For most histologic subtypes, the lung is the primary location of sarcomatous tumor seeding. ${ }^{2}$ The 5 -year overall survival (OS) across all subtypes of sarcoma is approximately $65 \% ; 5$-year OS for patients with pulmonary metastases ranges from $15 \%$ to $52 \%$. ${ }^{1,3,9,10}$ Furthermore, more than one half of patients who undergo complete gross resection experience recurrence of pulmonary disease..$^{8,11,12}$ In the absence of effective systemic therapies, metastatic STS remains a challenge to treat.

Pulmonary metastasectomy (PM) is well accepted for the treatment of selected patients with metastatic STS, with its use based on the rationale that clearance of metastatic disease is associated with improved patient outcomes. ${ }^{3,5,8,10}$ Patients who have undergone PM for STS have been found to survive 22 months longer than patients treated with nonoperative therapy. ${ }^{3}$ Similar benefits have been observed for patients with other solid tumors. ${ }^{8,13-15}$ Patient selection plays an important role in determining who may benefit from surgery, but indications related to outcomes remain unclear. There are no established guidelines for the performance of PM, and decisions to operate are often made on a case-by-case basis. ${ }^{16,17}$ Prognostic factors associated with survival have been identified but, in general, were derived from small series or mixed and heterogeneous registries. ${ }^{7-9,12,18,19}$ Bone sarcomas, for example, often are included with STS but may be managed with a different algorithm, given their responsiveness to chemotherapy. ${ }^{20}$ The purpose of this investigation was to identify factors associated with longer OS and disease-free recurrence after the first resection via the use of a large single-institution database of patients undergoing PM for STS. The identification of these factors will help thoracic surgeons determine which subset(s) of patients are most likely to benefit from PM.

\section{PATIENTS AND METHODS \\ Patient Selection}

The Thoracic Service at Memorial Sloan Kettering Cancer Center (MSKCC) prospectively maintains a database of patients undergoing PM for primary STS. From this database, we identified 803 patients who underwent PM for sarcoma between September 1991 and June 2014. Patients who had primary bone sarcomas $(n=35)$, underwent diagnostic resections $(n=194)$, underwent a PM at an outside hospital $(n=29)$, or did not undergo resection of their primary tumor $(n=6)$ were excluded. The remaining patients (539 who underwent 760 therapeutic-intent PMs) were reviewed (Figure 1). Patients were censored on the date of death or on the date of the last follow-up. We previously reported on $123(23 \%)$ of these patients, as part of an earlier (1982-1997) review. ${ }^{3}$ All data were collected with the approval of the Institutional Review Board at MSKCC.

\section{Clinicopathologic Variables}

Clinicopathologic variables related to each patient's demographic characteristics, primary tumor, metastatic disease, and medical and surgical treatment were obtained. Primary tumor histologic subtype, grade, and size were identified by review of pathology reports. Pathologic slides from outside institutions were obtained for internal verification of diagnoses, in the majority of cases; if slides were unavailable, external reports, at a minimum, were reviewed. Primary histologic subtypes represented by $<10$ patients were categorized as "other."

The initial disease-free interval (DFI) was defined from the time of primary tumor resection to the development of metastases, as defined by radiologic or pathologic evidence of disease. As previous studies have found significant differences in survival at 12 and 24 months, ${ }^{10,12}$ we evaluated recurrence by intervals of $<6$ months, between 6 and 12 months, between 12 and 24 months, and $>24$ months from resection of the primary tumor. Type of operation (minimally invasive or open), extent of resection (wedge resection, lobectomy, or pneumonectomy), and number of metastases resected were obtained by review of operative reports; completeness of resection was evaluated by the use of operative

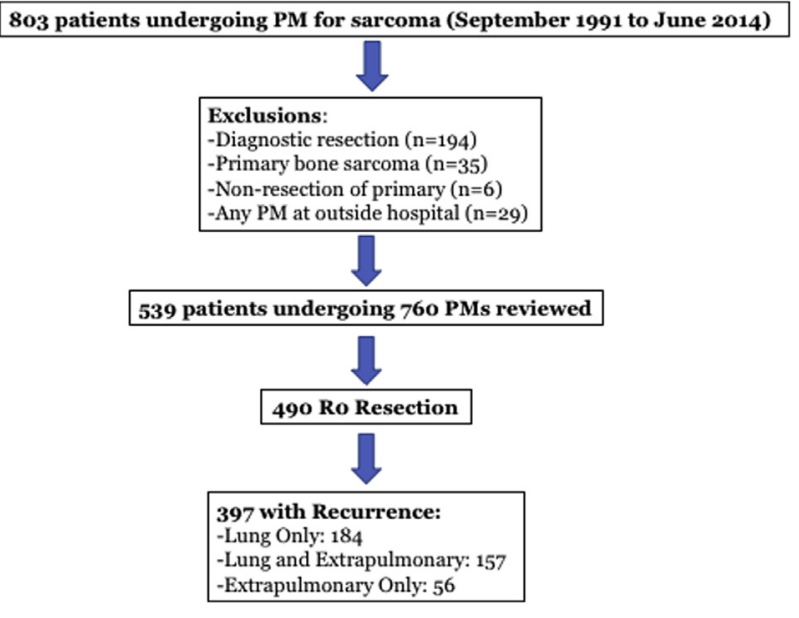

FIGURE 1. Database progression to final cohort of patients included for analysis. $P M$, Pulmonary metastasectomy. 
and pathology reports. For patients with tumors that were grossly unresectable at surgery or for patients who underwent only one procedure of a planned staged resection for bilateral disease, the number of pulmonary lesions was documented on the basis of preoperative radiologic results. Details of medical treatment were identified by review of the medical record.

\section{Survival}

OS and disease-free survival (DFS) were the primary endpoints of this study. OS was defined from the date of the first PM to the date of death or last follow-up. Date of death was obtained from clinical documentation or from information available through the Social Security Death Index. DFS was defined from the date of the first PM to the date of the first relapse at any site, as documented by radiologic or pathologic evidence, or the date of death from any cause (if without recurrence) and censored at the date of the last follow-up. For patients who had an R1 or R2 resection, the date of surgery was listed as the date of recurrence. Follow-up was conducted either at MSKCC or through local oncology offices with documentation transmitted to our institution. In the absence of this information, physician offices were contacted with regard to updates on recurrence and/or further treatment.

\section{Statistical Analysis}

OS and DFS were estimated by the Kaplan-Meier method, and associations between factors and survival were analyzed by use of the log-rank test and univariable Cox proportional hazards model. The number of nodules was dichotomized on the basis of the method of optimal cut-point estimation, which uses a maximally selected log-rank statistic to choose the cut-point that best stratifies the cohort. ${ }^{21}$ For the variable dichotomized by using the optimal cut-point method, $P$ values were adjusted for optimal search. ${ }^{21}$ Key interactions between factors of interest were examined via a Cox proportional hazards model for OS and DFS, including both main effects and the interaction term.

For multivariable models of OS and DFS, variable selection was guided by the all subset method with Akaike information criterion, ${ }^{22}$ including main and interaction terms with $P<.1$ from the univariable analyses. On the basis of the published literature identifying factors associated with OS and DFS in this population, ${ }^{3,10,19}$ some variables were chosen to remain in the multivariable models regardless of significance: histologic subtype of the primary tumor, grade of primary tumor (low vs high), and resection status (R0 vs R1 or R2). Overall $P$ values of categorical factors were calculated on the basis of Wald tests of linear hypotheses of the dummy variables. All statistical tests were 2-sided, and $P<.05$ is considered statistically significant. Statistical analyses were performed with R (version 3.0.1; R Development Core Team, the $\mathrm{R}$ Foundation for Statistical Computing, Vienna, Austria) with the "maxstat" and "glmulti" packages and Stata 13 (StataCorp, College Station, Tex).

\section{RESULTS \\ Patient Demographic and Clinical Characteristics}

Records for 539 patients were reviewed. Median age at diagnosis of the primary tumor was 51 years (range, 9-88 years), and median age at first PM was 54 years (range, $15-90$ years $) ; 58 \%(\mathrm{n}=312)$ of patients were female. The primary tumor was resected at MSKCC for 275 patients (51\%). Clinicopathologic characteristics are listed in Table 1. Leiomyosarcoma was the most common histologic subtype $(\mathrm{n}=169,31 \%)$, followed by pleomorphic sarcoma (PS)/malignant fibrous histiocytoma (MFH) $(\mathrm{n}=130$, $24 \%$ ). The most common location of the primary tumor was the extremities $(\mathrm{n}=249,46 \%)$. Most tumors were high grade $(\mathrm{n}=470,87 \%) ; 204(38 \%)$ were $>10 \mathrm{~cm}$.

The majority of patients $(n=373,69 \%)$ presented with pulmonary metastases only. A smaller number of patients presented with a simultaneous local recurrence $(\mathrm{n}=48$, $9 \%)$, extrapulmonary metastases $(n=38,7 \%)$, or both $(\mathrm{n}=9,2 \%)$. Synchronous metastases were present in 71 patients $(13 \%)$. Time to development of metastases from resection of the primary tumor was $<6$ months for 63 patients $(12 \%)$ and $>24$ months for 176 patients $(33 \%)$. Median time from diagnosis of the primary tumor to the development of metastases was 15.6 (25th, 75th percentile, $7.5,35.9)$ months. A single pulmonary metastasis was identified in 229 patients $(43 \%)$, whereas 138 patients (26\%) had $\geq 5$ lesions (range, $1-34$ lesions).

Seventy percent of patients $(\mathrm{n}=377)$ underwent PM as their initial treatment; $30 \%(\mathrm{n}=160)$ received induction chemotherapy for their metastases. Open procedures-consisting of thoracotomy $(\mathrm{n}=337)$, sternotomy $(\mathrm{n}=10)$, or clamshell procedures $(\mathrm{n}=26)$ were performed in $71 \%$ of patients $(\mathrm{n}=373)$. Ten patients with bilateral pulmonary metastases underwent combined open and minimally invasive procedures; in the survival analysis, these patients were included in the open group, because of their small numbers. Minimally invasive surgery (MIS) increased more than 4-fold from the first half to the second half of the study period ( 29 cases before 2004 vs 127 cases after 2004; Figure 2). Of the 156 minimally invasive procedures, $60 \%(\mathrm{n}=93)$ were done to resect a solitary pulmonary metastasis.

At least one benign nodule was excised in 174 patients $(32 \%)$; in total, 329 noncancerous lesions were resected. All patients included in this analysis had at least one malignant lesion demonstrated on pathologic examination. Wedge resection was the most common type of resection performed $(\mathrm{n}=422,78 \%)$. Complete $(\mathrm{R} 0)$ resection was achieved in $91 \%$ of patients $(n=490)$. After the initial PM, 49 patients $(9 \%)$ remained without evidence of disease and did not require further treatment. Whereas most of these patients underwent wedge resections and were treated with surgery alone, $27 \%(\mathrm{n}=13)$ underwent lobectomy and $27 \%(\mathrm{n}=13)$ also received preoperative chemotherapy. In contrast to patients who experienced a recurrence, patients in the disease-free group were more likely to have had a low-grade primary tumor $(P=.017)$ and a smaller number of pulmonary metastases $(P=.001)$. Twenty-nine percent of patients $(\mathrm{n}=154)$ underwent repeat PM.

\section{OS and DFS}

Median follow-up after the first PM was 27 months (range, 0-244 months). Median OS was 33.2 months (95\% confidence interval [CI], 29.9-37.1 months), and 5-year survival was $34 \%$ (Figure 3, A). Survivors were 
TABLE 1. Clinicopathologic characteristics of patients undergoing pulmonary metastasectomy for soft-tissue sarcoma $(\mathbf{N}=\mathbf{5 3 9})$

\begin{tabular}{|c|c|}
\hline Variable & No. $(\%)$ \\
\hline \multicolumn{2}{|l|}{ Sex } \\
\hline Male & $227(42)$ \\
\hline Female & $312(58)$ \\
\hline \multicolumn{2}{|l|}{ Histologic subtype } \\
\hline Leiomyosarcoma & $169(31)$ \\
\hline PS/MFH & $130(24)$ \\
\hline Synovial & $81(15)$ \\
\hline Other & $81(15)$ \\
\hline Fibrosarcoma & $33(6)$ \\
\hline Liposarcoma & $30(6)$ \\
\hline MPNST & $15(3)$ \\
\hline \multicolumn{2}{|l|}{ Site of primary tumor } \\
\hline Extremity & $249(46)$ \\
\hline Trunk & $65(12)$ \\
\hline $\mathrm{RP} /$ abdomen/pelvis & $65(12)$ \\
\hline Visceral-GU/GYN & $136(25)$ \\
\hline Head and neck & $24(5)$ \\
\hline \multicolumn{2}{|l|}{ Size of primary tumor, $\mathrm{cm}$} \\
\hline$\leq 10$ & $275(51)$ \\
\hline$>10$ & $204(38)$ \\
\hline Unknown & $60(11)$ \\
\hline \multicolumn{2}{|l|}{ Grade of primary tumor } \\
\hline Low & $62(12)$ \\
\hline High & $470(87)$ \\
\hline Unknown & $7(1)$ \\
\hline \multicolumn{2}{|l|}{ Status at presentation } \\
\hline Synchronous metastases & $71(13)$ \\
\hline Pulmonary metastases only & $373(69)$ \\
\hline Pulmonary metastases + primary LR & $48(9)$ \\
\hline Pulmonary metastases + EPM & $38(7)$ \\
\hline Pulmonary metastases + LR + EPM & $9(2)$ \\
\hline \multicolumn{2}{|l|}{ Interval to first metastasis } \\
\hline Synchronous metastases & $71(13)$ \\
\hline$<6 \mathrm{mo}$ & $63(12)$ \\
\hline 6-12 mo & 102 (19) \\
\hline $12-24 \mathrm{mo}$ & $127(24)$ \\
\hline$>24 \mathrm{mo}$ & $176(33)$ \\
\hline \multicolumn{2}{|l|}{ Laterality of disease } \\
\hline Unilateral & $341(63)$ \\
\hline Bilateral & $198(37)$ \\
\hline \multicolumn{2}{|l|}{ No. of pulmonary resections } \\
\hline 1 & $385(71)$ \\
\hline 2 & $110(20)$ \\
\hline 3 & $28(5)$ \\
\hline$\geq 4$ & $16(3)$ \\
\hline \multicolumn{2}{|l|}{ Chemotherapy } \\
\hline None & $354(66)$ \\
\hline Preoperative & $130(24)$ \\
\hline Postoperative & $23(4)$ \\
\hline Both & $30(6)$ \\
\hline \multicolumn{2}{|l|}{ Type of surgery } \\
\hline Open & $383(71)$ \\
\hline Minimally invasive & $156(29)$ \\
\hline
\end{tabular}

TABLE 1. Continued

\begin{tabular}{lc}
\hline \multicolumn{1}{c}{ Variable } & No. $(\%)$ \\
\hline Staged resection* & \\
No & $108(55)$ \\
Yes & $90(46)$ \\
No. of pulmonary metastases & \\
1 & $229(43)$ \\
2 & $87(16)$ \\
3 & $57(11)$ \\
4 & $28(5)$ \\
$\geq 5$ & $138(26)$ \\
Extent of resection & \\
Wedge & $422(78)$ \\
Lobectomy & $107(20)$ \\
Pneumonectomy & $10(2)$ \\
Resection outcome & \\
R0 & $490(91)$ \\
R1 & $18(3)$ \\
R2 & $31(6)$ \\
\hline$P S$, Pleomorphic sarcoma; $M F H$, malignant fibrous histiocytoma; $M P N S T$, \\
malignant peripheral nerve sheath tumor; $R P$, retroperitoneum; $G U / G Y N$, \\
genitourinary/gynecological; $L R$, local recurrence; $E P M$, extrapulmonary metastases. \\
$*$ Patients presenting with bilateral disease (n $=198)$.
\end{tabular}

followed for a median of 51 months and a mean of 76 months. Median time to recurrence was 6.8 months (95\% CI, 6.0-8.0 months; range, 0-107.0 months; Figure $3, B)$. After R0 pulmonary resection, $63 \%$ of the total cohort $(\mathrm{n}=341)$ experienced a recurrence in the lungs, $34 \%(\mathrm{n}=184)$ experienced recurrence only in the lungs, and $74 \%(n=397)$ developed recurrence at any site. Among patients with a solitary pulmonary metastasis, $72 \%(165 / 229)$ experienced recurrence at any site, $60 \%$ experienced recurrence in the lungs with or without extrapulmonary recurrence, and only $12 \%$ developed an isolated extrapulmonary recurrence. The median DFS in this group was 10.6 months, compared with 4.2 months for patients with $>1$ nodule $(P<.001)$.

The relationships between OS and various clinicopathologic factors are shown in Table 2. Histologic subtype and

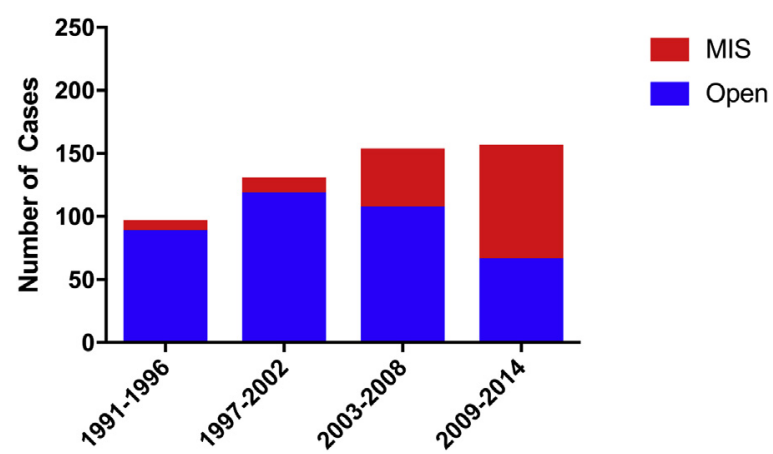

FIGURE 2. Minimally invasive surgery use (1991-2014). MIS, Minimally invasive surgery. 


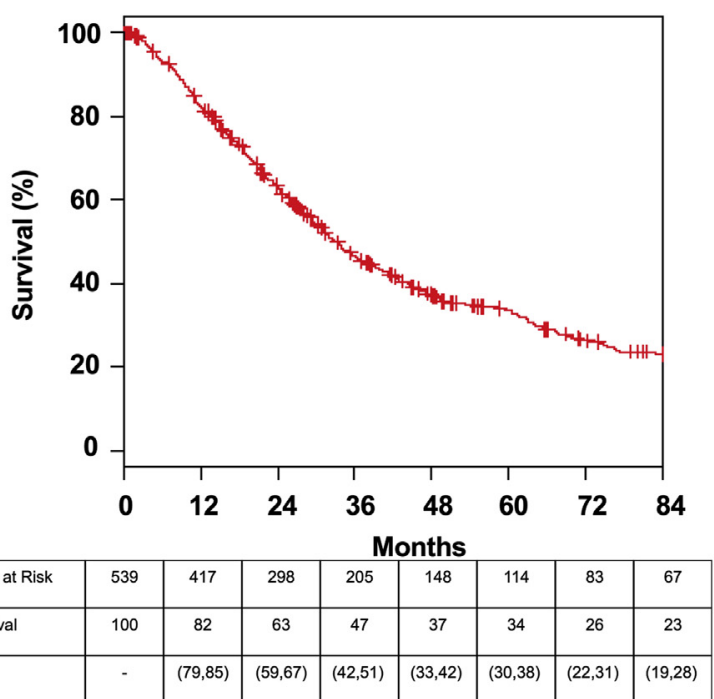

A

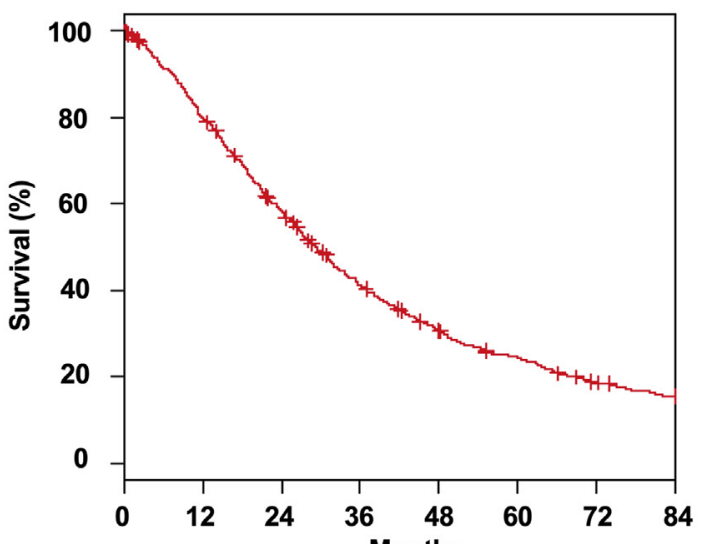

\begin{tabular}{|l|c|c|c|c|c|c|c|c|}
\hline Number at Risk & 539 & 162 & 87 & 65 & 49 & 36 & 27 & 24 \\
\hline$\%$ Survival & 88 & 31 & 18 & 15 & 12 & 10 & 9 & 8 \\
\hline $95 \% \mathrm{Cl}$ & - & $(27,35)$ & $(15,22)$ & $(12,19)$ & $(10,16)$ & $(8.14)$ & $(6,12)$ & $(6,11)$ \\
\hline
\end{tabular}

\section{B}

FIGURE 3. A, Overall and B, disease-free survival from first pulmonary metastasectomy. $\mathrm{CI}$, Confidence interval.

size of the primary tumor were significantly associated with OS. Patients who underwent PM for PS/MFH had the shortest median OS (23.6 months), whereas those who underwent PM for leiomyosarcoma had a median OS of 42.0 months $(P=.001$; Figure E1, $A)$. Although fibrosarcoma was associated with the longest median OS (65.2 months), it is notable that $42 \%$ of patients with this histologic subtype had low-grade primary tumors. Patients with smaller $(\leq 10 \mathrm{~cm})$ primary tumors had an OS of 35.6 months, compared with 26.0 months for those with tumors $>10 \mathrm{~cm}(P=.004)$. Low-grade primary tumors also were associated with better survival $(P<.001)$. No significant differences were observed between patients aged $<50$ years and those aged $\geq 50$ years $(P=.832)$.
TABLE 2. Univariable log-rank tests of overall and disease-free survival

\begin{tabular}{|c|c|c|c|c|c|}
\hline Variable & $\begin{array}{l}\text { No. } \\
(\%)\end{array}$ & $\begin{array}{l}\text { Median } \\
\text { OS, mo }\end{array}$ & $\begin{array}{c}P \\
\text { value }\end{array}$ & $\begin{array}{c}\text { Median } \\
\text { DFS, mo }\end{array}$ & $\begin{array}{c}P \\
\text { value } \\
\end{array}$ \\
\hline Age, $y$ & & & .832 & & .562 \\
\hline$<50$ & $205(38)$ & 31.1 & & 6.4 & \\
\hline$\geq 50$ & $334(62)$ & 34.1 & & 6.8 & \\
\hline Histologic subtype & & & .001 & & .044 \\
\hline Leiomyosarcoma & $169(31)$ & 42.0 & & 5.9 & \\
\hline PS/MFH & $130(24)$ & 23.6 & & 4.2 & \\
\hline Synovial & $81(15)$ & 32.3 & & 5.3 & \\
\hline Other & $81(15)$ & 26.7 & & 6.7 & \\
\hline Fibrosarcoma & $33(6)$ & 65.2 & & 12.6 & \\
\hline Liposarcoma & $30(6)$ & 27.9 & & 8.8 & \\
\hline MPNST & $15(3)$ & 32.9 & & 4.6 & \\
\hline Site of primary tumor & & & .001 & & .105 \\
\hline Extremity & $249(46)$ & 29.28 & & 5.2 & \\
\hline Visceral-GU/GYN & $135(25)$ & 43.0 & & 6.7 & \\
\hline Trunk & $65(12)$ & 23.9 & & 5.8 & \\
\hline $\mathrm{RP} /$ abdomen/pelvis & $65(12)$ & 35.8 & & 6.1 & \\
\hline Head and neck & $24(4)$ & 45.5 & & 7.0 & \\
\hline Size of primary tumor & & & .004 & & .019 \\
\hline$\leq 10 \mathrm{~cm}$ & $275(51)$ & 35.6 & & 5.8 & \\
\hline$>10 \mathrm{~cm}$ & $204(38)$ & 26.0 & & 5.0 & \\
\hline Grade of primary tumor & & & $<.001$ & & .001 \\
\hline Low & $62(12)$ & 71.8 & & 11.5 & \\
\hline High & $470(87)$ & 30.8 & & 5.3 & \\
\hline Interval to first metastasis & & & $<.001$ & & $<.001$ \\
\hline Synchronous & $71(13)$ & 36.6 & & 3.0 & \\
\hline$<6 \mathrm{mo}$ & $63(12)$ & 18.6 & & 3.8 & \\
\hline 6-12 mo & $102(19)$ & 29.3 & & 4.0 & \\
\hline $12-24 \mathrm{mo}$ & $127(24)$ & 31.5 & & 6.1 & \\
\hline$>24$ mo & $176(33)$ & 46.2 & & 11.6 & \\
\hline No. of pulmonary metastases & & & $<.001$ & & $<.001$ \\
\hline$\leq 1$ & $229(43)$ & 46.2 & & 11.8 & \\
\hline$>1$ & $310(57)$ & 26.8 & & 5.2 & \\
\hline Presentation & & & $<.001$ & & $<.001$ \\
\hline Pulm mets only & $373(69)$ & 37.1 & & 6.8 & \\
\hline Pulm mets + LR & $48(9)$ & 22.1 & & 3.2 & \\
\hline Pulm mets + EPM & $38(7)$ & 21.2 & & 4.4 & \\
\hline Pulm mets + LR + EPM & $9(2)$ & 29.3 & & 3.2 & \\
\hline Type of surgery & & & .007 & & .121 \\
\hline Open & $383(71)$ & 29.9 & & 5.3 & \\
\hline Minimally invasive & $156(29)$ & 44.3 & & 6.7 & \\
\hline Resection extent & & & .035 & & .59 \\
\hline Wedge & $422(78)$ & 34.3 & & 5.5 & \\
\hline Lobectomy & $107(20)$ & 23.0 & & 5.3 & \\
\hline Pneumonectomy & $10(2)$ & 27.0 & & 10.6 & \\
\hline Resection outcome & & & .003 & & N/A \\
\hline R0 & $490(91)$ & 33.8 & & 6.6 & \\
\hline $\mathrm{R} 1 / \mathrm{R} 2$ & $49(9)$ & 25.4 & & N/A & \\
\hline Preoperative chemo & & & $<.001$ & & .004 \\
\hline No & $377(70)$ & 38.6 & & 6.36 & \\
\hline Yes with response & $92(17)$ & 26.6 & & 4.32 & \\
\hline Yes without response & $64(12)$ & 19.9 & & 3.72 & \\
\hline
\end{tabular}

$O S$, Overall survival; $D F S$, disease-free survival; $P S$, pleomorphic sarcoma; $M F H$, malignant fibrous histiocytoma; MPNST, malignant peripheral nerve sheath tumor; $G U /$ $G Y N$, genitourinary/gynecological; $R P$, retroperitoneum; Pulm mets, pulmonary metastasis; $L R$, local recurrence; $E P M$, extrapulmonary metastases; $N / A$, not applicable. 
Differences in OS were observed on the basis of disease presentation: synchronous pulmonary metastases, metachronous pulmonary metastases only, and metachronous pulmonary metastases with local recurrence and/or extrapulmonary metastases $(P<.001)$. Presentation with metachronous pulmonary metastases only was associated with the longest OS (37.1 months). Interestingly, although their numbers were small, patients presenting with synchronous pulmonary metastases did not have worse OS. Follow-up analysis demonstrated that a large proportion of these patients $(42 \%)$ had a primary histologic subtype of leiomyosarcoma. Additionally, patients with synchronous pulmonary metastases were more likely to have received chemotherapy before surgery $(58 \%$ vs $26 \% ; P<.001)$, and $73 \%$ of these patients experienced stability or regression of disease with treatment. Analysis of DFI (Figure E1, B) demonstrated that patients who developed pulmonary metastatic disease within 6 months of resection of their primary tumor had significantly worse survival than patients who developed metastases $>2$ years after resection $(P<.001)$. Likewise, $>1$ metastasis was associated with a decrease in OS of 19 months $(P<.001)$.

Differences in OS also were identified on the basis of type of treatment. Patients who underwent chemotherapy before PM had poorer OS than patients who underwent surgery as the first treatment modality $(P<.001)$. Patients with synovial sarcomas $(46 \%)$ and PS $(30 \%)$ most commonly received chemotherapy. Patients with a greater number of pulmonary metastases $(P<.001)$ and those with extrapulmonary metastases $(P<.001)$ also were more likely to receive chemotherapy. This finding likely reflects a patient selection bias based on initial burden of disease. Median OS for patients who underwent minimally invasive resection was 44 months, compared to 30 months for patients who underwent open PM $(P=.007$; Figure E1, $C)$. Similarly, R0 resection was associated with a survival benefit of 8 months in terms of median survival, compared with $\mathrm{R} 1 / \mathrm{R} 2$ resection (33.8 months [ $95 \% \mathrm{CI}, 30.8-39.2$ ] vs 25.4 months [ $95 \% \mathrm{CI}, 16.5-31.5] ; P=.003)$. Patients with a greater number of pulmonary metastases were more likely to undergo an open procedure $(P<.001)$ and were more likely to have an $\mathrm{R} 1$ or $\mathrm{R} 2$ resection $(P<.001)$. There was no difference in the rate of $\mathrm{R} 0$ resection between open and minimally invasive procedures $(10 \%$ in open vs $7.7 \%$ in minimally invasive procedures; $P=.5$ ). Sublobar resection was associated with better OS, compared with more-extensive procedures such as lobectomy or pneumonectomy $(P=.035)$-this, again, is likely a reflection of the burden of disease.

The majority of patients $(74 \%)$ experienced a relapse at any site after R0 resection. As was observed for OS, primary tumor histologic subtype $(P=.044)$, size $(P=.019)$, and grade $(P=.001)$ were associated with DFS: PS/MFH tumors, tumors $>10 \mathrm{~cm}$, and high-grade tumors were associated with shorter DFI. Patients with synchronous metastases $(P<.001)$ and those with $>1$ lesion $(P<.001)$ also had shorter DFS. Neither type of surgery nor extent of resection was significantly associated with DFS $(P=.121$ and $P=.59$, respectively).

\section{Univariable and Multivariable Analyses of OS and DFS}

Results from univariable and multivariable Cox models for OS are reported in Table 3. In univariable analysis, year of pulmonary resection as a continuous variable was not significantly associated with hazard of death $(P=.2)$. There were no significant interactions between prespecified clinical covariates of interest in terms of hazard of death (Table E1). Leiomyosarcoma was associated with a reduced hazard of death, compared with PS/MFH (hazard ratio [HR], 0.66; 95\% CI, 0.48-0.89; $P=.007)$. Primary tumor size remained significant on multivariable analysis: tumors $>10 \mathrm{~cm}$ had an associated greater hazard of death (HR, $1.38 ; 95 \% \mathrm{CI}, 1.10-1.73 ; P=.006)$. Site of primary tumor was not selected into the final model despite being significant in the univariable model (overall $P=.0011$ ). Interestingly, histologic grade was not associated with risk of death (HR, $1.23 ; 95 \% \mathrm{CI}, 0.79-1.91 ; P=.4)$. DFI of at least 1 year before the development of metastatic disease was associated with improved prognosis, compared with $<6$ months (HR, 0.54; 95\% CI, 0.37-0.79; $P=.001$ ), with $>24$ months being most beneficial (HR, 0.47; $95 \%$ CI, 0.32-0.69; $P<.001)$. Having $>1$ pulmonary metastasis was associated with reduced survival (HR, $1.57 ; 95 \% \mathrm{CI}$, 1.21-2.02; $P=.001)$. The presence of synchronous extrapulmonary sites of disease was significantly associated with hazard of death (overall $P=.0013$ ). Compared with pulmonary metastases only, simultaneous local recurrence (HR, $1.89 ; 95 \%$ CI, 1.29-2.77; $P=.001$ ) and simultaneous extrapulmonary metastases (HR, 1.78; 95\% CI, 1.15-2.74; $P=.009)$ were associated with greater hazard of death. Minimally invasive resection (HR, $0.73 ; 95 \% \mathrm{CI}$, $0.56-0.96 ; P=.023)$ additionally was associated with a reduced risk of death. Extent of resection $(P=.3$ for lobectomy, $P=.2$ for pneumonectomy, compared with wedge resection) and completeness of resection $(P=.7)$ were not associated with hazard of death.

Univariable and multivariable Cox models for the hazard of disease (recurrence or death) are presented in Table 4. In univariable analysis, year of pulmonary resection as a continuous variable was not significantly associated with hazard of death $(P=.4)$. There were no significant interactions between prespecified clinical covariates of interest in terms of hazard of disease (Table E2). Few factors were associated with a reduced risk of recurrence on multivariable analysis. Greater than 1 pulmonary metastasis (HR, 1.81; 95\% CI, 1.44-2.28; $P<.001$ ) was associated with a greater hazard of recurrence or death. 
TABLE 3. Univariable and multivariable Cox proportional hazards model for risk of death

\begin{tabular}{|c|c|c|c|c|}
\hline Variable & Univariable Cox hazard ratio $(95 \%$ CI $)$ & $P$ value & Multivariable Cox hazard ratio $(95 \% \mathrm{CI})$ & $P$ value \\
\hline Increasing age at $\mathrm{PM}$ & $1.00(1.00-1.01)$ & .5 & - & - \\
\hline Year of PM & $0.99(0.97-1.00)$ & .2 & - & - \\
\hline \multicolumn{5}{|l|}{ Sex } \\
\hline Female* & 1.00 & & - & - \\
\hline Male & $1.26(1.02-1.55)$ & .028 & - & - \\
\hline \multicolumn{5}{|l|}{ Histologic subtype } \\
\hline $\mathrm{PS} / \mathrm{MFH}^{*}$ & 1.00 & & 1.00 & \\
\hline Leiomyosarcoma & $0.57(0.44-0.75)$ & $<.001$ & $0.66(0.48-0.89)$ & .007 \\
\hline Synovial & $0.78(0.57-1.08)$ & .14 & $0.93(0.65-1.32)$ & .7 \\
\hline Other & $0.61(0.43-0.86)$ & .005 & $0.85(0.57-1.26)$ & .4 \\
\hline Fibrosarcoma & $0.44(0.27-0.70)$ & .001 & $0.60(0.35-1.03)$ & .064 \\
\hline Liposarcoma & $0.73(0.46-1.14)$ & .2 & $0.86(0.53-1.41)$ & .6 \\
\hline MPNST & $0.92(0.48-1.77)$ & .8 & $1.43(0.70-2.92)$ & .3 \\
\hline \multicolumn{5}{|l|}{ Site of primary tumor } \\
\hline Extremity* & 1.00 & & - & - \\
\hline Visceral-GU/GYN & $0.66(0.51-0.86)$ & .002 & - & - \\
\hline Trunk & $1.33(0.96-1.83)$ & .084 & - & - \\
\hline $\mathrm{RP} / \mathrm{abdomen} / \mathrm{pelvis}$ & $0.94(0.68-1.30)$ & .7 & - & - \\
\hline Head and neck & $0.68(0.41-1.11)$ & .13 & - & - \\
\hline \multicolumn{5}{|l|}{ Size of primary tumor } \\
\hline$\leq 10 \mathrm{~cm}^{*}$ & 1.00 & & 1.00 & \\
\hline$>10 \mathrm{~cm}$ & $1.37(1.11-1.71)$ & .004 & $1.38(1.10-1.73)$ & .006 \\
\hline \multicolumn{5}{|l|}{ Grade of primary tumor } \\
\hline Low ${ }^{*}$ & 1.00 & & 1.00 & \\
\hline High & $2.01(1.40-2.88)$ & $<.001$ & $1.23(0.79-1.91)$ & .4 \\
\hline \multicolumn{5}{|l|}{ Interval to first metastasis } \\
\hline$<6 \mathrm{mo}^{*}$ & 1.00 & & 1.00 & \\
\hline $6-12 \mathrm{~m}$ & $0.68(0.48-0.97)$ & .035 & $0.80(0.55-1.16)$ & .2 \\
\hline $12-24 \mathrm{mo}$ & $0.56(0.40-0.78)$ & .001 & $0.54(0.37-0.79)$ & .001 \\
\hline$>24 \mathrm{mo}$ & $0.40(0.29-0.55)$ & $<.001$ & $0.47(0.32-0.69)$ & $<.001$ \\
\hline Synchronous & $0.54(0.36-0.80)$ & .002 & $0.49(0.32-0.77)$ & .002 \\
\hline \multicolumn{5}{|l|}{ No. of pulmonary metastases } \\
\hline$\leq 1^{*}$ & 1.00 & & 1.00 & \\
\hline$>1$ & $1.80(1.45-2.23)$ & $<.001$ & $1.57(1.21-2.02)$ & .001 \\
\hline \multicolumn{5}{|l|}{ Presentation } \\
\hline Pulm mets only* & 1.00 & & 1.00 & \\
\hline Pulm mets + LR & $1.73(1.22-2.44)$ & .002 & $1.89(1.29-2.77)$ & .001 \\
\hline Pulm mets + EPM & $2.02(1.39-2.93)$ & $<.001$ & $1.78(1.15-2.74)$ & .009 \\
\hline Pulm mets $+\mathrm{LR}+\mathrm{EPM}$ & $1.19(0.53-2.68)$ & .7 & $0.88(0.37-2.10)$ & .8 \\
\hline \multicolumn{5}{|l|}{ Type of surgery } \\
\hline Open* & 1.00 & & 1.00 & \\
\hline Minimally invasive & $0.71(0.56-0.91)$ & .007 & $0.73(0.56-0.96)$ & .023 \\
\hline \multicolumn{5}{|l|}{ Extent of resection } \\
\hline Wedge* & 1.00 & & 1.00 & \\
\hline Lobectomy & $1.38(1.07-1.77)$ & .013 & $1.16(0.86-1.57)$ & .3 \\
\hline Pneumonectomy & $1.36(0.72-2.55)$ & .3 & $1.53(0.75-3.11)$ & .2 \\
\hline \multicolumn{5}{|l|}{ Resection outcome } \\
\hline $\mathrm{R} 0 *$ & 1.00 & & 1.00 & \\
\hline $\mathrm{R} 1 / \mathrm{R} 2$ & $1.67(1.19-2.35)$ & .003 & $1.06(0.72-1.56)$ & .7 \\
\hline \multicolumn{5}{|l|}{ Preoperative chemo } \\
\hline $\mathrm{No}^{*}$ & 1.00 & & & \\
\hline Yes with response & $1.57(1.20-2.07)$ & .001 & $1.16(0.83-1.62)$ & .4 \\
\hline Yes without response & $2.04(1.51-2.77)$ & $<.001$ & $1.65(1.15-2.36)$ & .007 \\
\hline
\end{tabular}


TABLE 4. Multivariable Cox proportional hazards model for risk of recurrence

\begin{tabular}{|c|c|c|c|c|}
\hline Variable & Univariable Cox hazard ratio $(95 \%$ CI) & $P$ value & Multivariable Cox hazard ratio $(95 \%$ CI $)$ & $P$ value \\
\hline Increasing age at PM & $1.00(0.99,1.01)$ & .9 & - & - \\
\hline Year of PM & $0.99(0.98,1.01)$ & .4 & - & - \\
\hline \multicolumn{5}{|l|}{ Sex } \\
\hline Female* & 1.00 & & - & - \\
\hline Male & $1.13(0.93,1.37)$ & .2 & - & - \\
\hline \multicolumn{5}{|l|}{ Histologic subtype } \\
\hline PS/MFH* & 1.00 & & 1.00 & \\
\hline Leiomyosarcoma & $0.79(0.61-1.02)$ & .071 & $0.83(0.63-1.10)$ & .2 \\
\hline Synovial & $0.84(0.61-1.17)$ & .3 & $1.02(0.72-1.44)$ & .9 \\
\hline Other & $0.66(0.48-0.91)$ & .012 & $0.93(0.65-1.33)$ & .7 \\
\hline Fibrosarcoma & $0.61(0.39-0.94)$ & .026 & $0.79(0.48-1.31)$ & .4 \\
\hline Liposarcoma & $0.79(0.52-1.22)$ & .3 & $0.93(0.60-1.46)$ & .8 \\
\hline MPNST & $1.03(0.54-1.98)$ & .9 & $1.62(0.83-3.16)$ & .2 \\
\hline \multicolumn{5}{|l|}{ Site of primary tumor } \\
\hline Extremity* & 1.00 & & - & - \\
\hline Visceral-GU/GYN & $0.66(0.51-0.86)$ & .002 & - & - \\
\hline Trunk & $1.33(0.96-1.83)$ & .084 & - & - \\
\hline $\mathrm{RP} / \mathrm{abdomen/pelvis}$ & $0.94(0.68-1.30)$ & .7 & - & - \\
\hline Head and neck & $0.68(0.41-1.11)$ & .13 & - & - \\
\hline \multicolumn{5}{|l|}{ Size of primary tumor, $\mathrm{cm}$} \\
\hline$\leq 10^{*}$ & 1.00 & & 1.00 & \\
\hline$>10$ & $1.29(1.05-1.58)$ & .016 & $1.21(0.98-1.51)$ & .077 \\
\hline \multicolumn{5}{|l|}{ Grade of primary tumor } \\
\hline Low $^{*}$ & 1.00 & & 1.00 & \\
\hline High & $1.72(1.24-2.38)$ & .001 & $1.19(0.81-1.75)$ & .4 \\
\hline \multicolumn{5}{|l|}{ Interval to first metastasis } \\
\hline$<6 \mathrm{mo}^{*}$ & 1.00 & & 1.00 & \\
\hline $6-12 \mathrm{mo}$ & $0.82(0.57-1.17)$ & .3 & $0.88(0.61-1.28)$ & .5 \\
\hline $12-24 \mathrm{mo}$ & $0.66(0.47-0.93)$ & .016 & $0.56(0.40-0.81)$ & .002 \\
\hline$>24 \mathrm{mo}$ & $0.46(0.34-0.64)$ & $<.001$ & $0.52(0.36-0.75)$ & $<.001$ \\
\hline Synchronous & $0.83(0.56-1.23)$ & .4 & $0.74(0.49-1.14)$ & .2 \\
\hline \multicolumn{5}{|l|}{ No. pulmonary metastases } \\
\hline$\leq 1 *$ & 1.00 & & 1.00 & \\
\hline$>1$ & $1.88(1.54-2.29)$ & $<.001$ & $1.81(1.44-2.28)$ & $<.001$ \\
\hline \multicolumn{5}{|l|}{ Presentation } \\
\hline Pulm mets only* & 1.00 & & 1.00 & \\
\hline Pulm mets + LR & $1.62(1.11-2.36)$ & .012 & $2.01(1.33-3.03)$ & .001 \\
\hline Pulm mets + EPM & $1.53(1.04-2.27)$ & .031 & $1.69(1.11-2.59)$ & .015 \\
\hline Pulm mets $+\mathrm{LR}+\mathrm{EPM}$ & $2.18(1.03-4.63)$ & .042 & $1.81(0.78-4.17)$ & .2 \\
\hline \multicolumn{5}{|l|}{ Type of surgery } \\
\hline Open* & 1.00 & & - & - \\
\hline Minimally invasive & $0.85(0.69-1.06)$ & .15 & - & - \\
\hline \multicolumn{5}{|l|}{ Extent of resection } \\
\hline Wedge* & 1.00 & & 1.00 & \\
\hline Lobectomy & $1.12(0.88-1.43)$ & .4 & $1.05(0.79-1.39)$ & .7 \\
\hline Pneumonectomy & $0.94(0.50-1.77)$ & .9 & $1.11(0.54-2.26)$ & .8 \\
\hline \multicolumn{5}{|l|}{ Resection outcome } \\
\hline $\mathrm{R} 0 *$ & 1.00 & & 1.00 & \\
\hline $\mathrm{R} 1 / \mathrm{R} 2$ & $2.12(0.53-8.54)$ & .3 & $2.80(0.57-13.77)$ & .2 \\
\hline \multicolumn{5}{|l|}{ Preoperative chemo } \\
\hline No* & 1.00 & & - & - \\
\hline Yes with response & $1.35(1.04-1.77)$ & .025 & - & - \\
\hline Yes without response & $1.25(0.90-1.73)$ & .2 & - & - \\
\hline
\end{tabular}


DFI of $>24$ months from the time of resection of the primary tumor was protective against recurrence or death (HR, 0.52; 95\% CI, 0.36-0.75; $P<.001$ ). Patients presenting with either synchronous local recurrence (HR, $2.01 ; 95 \%$ CI, 1.33-3.03; $P=.001)$ or synchronous extrapulmonary metastases (HR, 1.69; 95\% CI, $1.11-2.59 ; P=.015)$ also were more likely to experience recurrence or death. Histologic subtype, size and grade of the primary tumor, and extent of resection were not associated with hazard of recurrence or death.

\section{DISCUSSION}

Traditional factors for the consideration of PM include control of the primary tumor, complete resection of disease, and the absence of a better alternative treatment. ${ }^{23,24}$ Previous studies have reported a survival benefit with PM. ${ }^{3,7,8}$ The International Registry of Lung Metastases analyzed the long-term survival of 5206 patients undergoing PM, of whom 2173 had primary sarcoma. Their findings demonstrated that resectable disease, longer DFI, and solitary pulmonary metastasis were associated with improved OS. The recurrence rate after PM, for combined bone sarcoma and STS, was $64 \%$ in their analysis. ${ }^{8}$

Our results indicate that therapeutic-intent PM for STS can be associated with prolonged survival. The median survivals in our study (OS, 33.2 months; DFS, 6.8 months) are comparable with those in previous studies. $3,7,19,25$ Furthermore, we have identified positive prognostic factors, including leiomyosarcoma histologic subtype, primary tumor size $\leq 10 \mathrm{~cm}$, DFI $\geq 1$ year, absence of synchronous extrapulmonary metastases or local recurrence, and singular pulmonary metastasis. Longer DFI, presentation with metachronous pulmonary metastases only, and 1 pulmonary metastasis were associated with longer DFS.

Histologic subtype has been variably reported as a prognostic factor for survival. A recent study examining 155 patients who underwent PM for bone sarcoma $(n=47)$ or STS $(n=108)$ found longer OS among patients with leiomyosarcoma and shorter OS among patients with liposarcoma or synovial sarcoma. ${ }^{19}$ Other reports, however, failed to find a difference in OS between sarcoma subtypes. $9,10,25,26$ Moreover, associations have been inconsistently found for age at treatment, grade of the primary tumor, and extent of lung resection., 10,19,27 The present study differs from previous publications in that we used a larger single-institution cohort, which increases the power to potentially identify significant differences, and we focused on STS exclusively to enhance the homogeneity of the study population.

As mentioned, complete resection of metastases has been touted as an important determinant of outcomes. ${ }^{3,8,10,13,27-29}$ However, recent publications have demonstrated that positive margins are not associated with shorter OS..$^{9,19,30}$
Our findings similarly failed to demonstrate a significant difference in survival, presumably because of the small numbers of such resections ( $\mathrm{R} 1=3 \% ; \mathrm{R} 2=6 \%$ ). This may reflect the accuracy with which we selected patients to operate on, as R0 resection was achieved in $>90 \%$ of patients who underwent PM for STS in our study.

Open versus minimally invasive metastasectomy has been debated with respect to resection of all pulmonary metastases. $^{25,31}$ More than 25 years ago our group previously reported that manual palpation of the lung identifies up to $25 \%$ more pulmonary metastases than computed tomography scan. ${ }^{32}$ Even though computed tomography technology has improved, a $20 \%$ failure rate for detection of pulmonary metastases still exists, when intraoperative assessment is compared with preoperative imaging. ${ }^{31}$ However, not all nonimaged lesions are cancerous. ${ }^{31}$ In our study $18 \%$ of patients undergoing minimally invasive resection had at least 1 noncancerous lesion excised, compared with $38 \%$ in the open group $(P<.001)$.

In this contemporary study, we observed a robust increase in the use of MIS over time. Our results illustrate that minimally invasive resections are not associated with shorter OS or increased risk of recurrence. MIS is most commonly used for peripheral, low-volume metastatic disease $-81 \%$ of minimally invasive cases $(n=126)$ were for resection of 1 or 2 pulmonary metastases. The reduced risk associated with MIS is likely secondary to patient selection factors. Other recent studies have noted improved survival with minimally invasive resections for similar reasons. ${ }^{19}$

A current clinical trial on the role of PM for colorectal cancer metastases aims to discern whether PM increases OS relative to observation. ${ }^{7,33}$ Results are still pending and may not be readily extrapolated to STS, which is a more difficult disease to study in a randomized, prospective manner given the relative low incidence of the disease. Currently, the existing literature on STS suggests that failure to perform PM predicts worse survival. ${ }^{3,5}$ Our results indicate that the preoperative determination of disease characteristics can assist surgeons in selecting patients who may achieve longer survival with PM. Disease management teams, used at our institution with the goal of evaluating the aforementioned prognostic factors, provide a multidisciplinary approach in determining appropriate treatment, which may include not performing a PM. The excellent result of a $90 \%$ R0 resection rate supports PM for sarcomatous pulmonary metastases.

Several limitations exist in our study. First, STS is a heterogeneous disease with varied histologic subtypes that we have analyzed collectively. We also acknowledge there is no control group with which to compare outcomes, and we are thus unable to directly evaluate patients who underwent PM versus those who underwent observation. The number of metastases used in our analyses was based on 
operative and pathologic reports performed to confirm that lesions removed were malignant. We acknowledge, however, that the decision to operate will factor in the number of lesions identified on preoperative radiography. For patients with extrapulmonary sites of disease, data on treatment of these other sites were not available, and we are unable to further stratify survival by this variable. Last, confounding factors exist in determining prognostic factors for survival. To this extent, we have used a multivariable analysis inclusive of such factors, but yield that prospective data would provide higher-level evidence.

While the evolution of precision medicine has led to its expanding role in cancer treatment, the rarity and heterogeneity of STS have challenged its implementation for this disease. ${ }^{34}$ The underlying mechanisms governing metastases in these mesenchymal cancers are not fully understood. ${ }^{35}$ Cytotoxic agents remain first-line treatments for metastatic STS, and survival remains poor. ${ }^{20}$ However, initial efforts in genomic profiling for STS are now finding some success in identifying putative targets. Sarcomas arising from the bone and gastrointestinal stromal tumors are 2 established examples in which specific translocations and mutations have guided treatment strategies. ${ }^{2}$ At least one targeted drug, the tyrosine kinase inhibitor pazopanib, is now approved as a second-line therapy for metastatic STS. ${ }^{34}$ Additional therapies aimed at the insulin growth factor and mTOR pathways, as well as at mutations in ALK or MET, are undergoing clinical trials. ${ }^{20}$

\section{CONCLUSIONS}

Using a large, prospectively maintained, singleinstitution database, we have identified prognostic factors for patients with metastatic STS undergoing PM. Until a randomized clinical trial for STS pulmonary metastases is completed, if ever, PM will continue to be viewed as an effective management strategy for selected patients with this disease. While we continue to pursue a better understanding of the underlying mechanisms governing the biology of STS metastases and further identify druggable targets, PM remains the best available treatment for STS pulmonary metastases.

\section{Webcast}

You can watch a Webcast of this AATS meeting presentation by going to: http://webcast.aats.org/2016/Video/Monday/ 05-16-16_Ballroom_IV_1615_Chudgar-800.mp4.

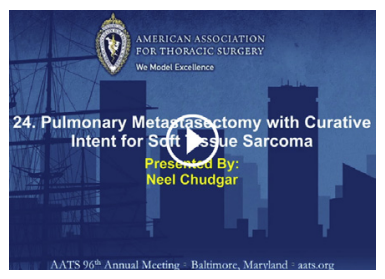

\section{Conflict of Interest Statement}

Authors have nothing to disclose with regard to commercial support.

\section{References}

1. Siegel RL, Miller KD, Jemal A. Cancer statistics, 2015. CA Cancer J Clin. 2015; 65:5-29.

2. Brennan MF, Antonescu CR, Moraco N, Singer S. Lessons learned from the study of 10,000 patients with soft tissue sarcoma. Ann Surg. 2014;260:416-21.

3. Billingsley KG, Burt ME, Jara E, Ginsberg RJ, Woodruff JM, Leung DH, et al. Pulmonary metastases from soft tissue sarcoma: analysis of patterns of diseases and postmetastasis survival. Ann Surg. 1999;229:602-10.

4. Coindre JM, Terrier P, Guillou L, Le Doussal V, Collin F, Ranchere D, et al. Predictive value of grade for metastasis development in the main histologic types of adult soft tissue sarcomas: a study of 1240 patients from the French Federation of Cancer Centers Sarcoma Group. Cancer. 2001;91:1914-26.

5. Smith R, Demmy TL. Pulmonary metastasectomy for soft tissue sarcoma. Surg Oncol Clin N Am. 2012;21:269-86.

6. Potter DA, Glenn J, Kinsella T, Glatstein E, Lack EE, Restrepo C, et al. Patterns of recurrence in patients with high-grade soft-tissue sarcomas. J Clin Oncol. 1985;3:353-66.

7. Treasure T, Fiorentino F, Scarci M, Moller H, Utley M. Pulmonary metastasectomy for sarcoma: a systematic review of reported outcomes in the context of Thames Cancer Registry data. BMJ Open. 2012;2:PMC3488730.

8. Pastorino U, Buyse M, Friedel G, Ginsberg RJ, Girard P, Goldstraw P, et al. Long-term results of lung metastasectomy: prognostic analyses based on 5206 cases. J Thorac Cardiovasc Surg. 1997;113:37-49.

9. Predina JD, Puc MM, Bergey MR, Sonnad SS, Kucharczuk JC, Staddon A, et al. Improved survival after pulmonary metastasectomy for soft tissue sarcoma. J Thorac Oncol. 2011;6:913-9.

10. Smith R, Pak Y, Kraybill W, Kane JM III. Factors associated with actual long-term survival following soft tissue sarcoma pulmonary metastasectomy. Eur J Surg Oncol. 2009;35:356-61.

11. Gadd MA, Casper ES, Woodruff JM, McCormack PM, Brennan MF. Development and treatment of pulmonary metastases in adult patients with extremity soft tissue sarcoma. Ann Surg. 1993;218:705-12.

12. Weiser MR, Downey RJ, Leung DH, Brennan MF. Repeat resection of pulmonary metastases in patients with soft-tissue sarcoma. J Am Coll Surg. 2000;191:184-90.

13. Casiraghi M, De Pas T, Maisonneuve P, Brambilla D, Ciprandi B, Galetta D, et al. A 10-year single-center experience on 708 lung metastasectomies: the evidence of the "international registry of lung metastases" J Thorac Oncol. 2011;6: $1373-8$.

14. Hornbech K, Ravn J, Steinbruchel DA. Outcome after pulmonary metastasectomy: analysis of 5 years consecutive surgical resections 2002-2006. J Thorac Oncol. 2011;6:1733-40.

15. Nichols FC. Pulmonary metastasectomy. Thorac Surg Clin. 2012;22:91-9.

16. Treasure T, Utley M. Surgical removal of asymptomatic pulmonary metastases: time for better evidence. BMJ. 2013;346:f824.

17. Van Raemdonck D, Friedel G. The European Society of Thoracic Surgeons lung metastasectomy project. J Thorac Oncol. 2010;5:S127-9.

18. Dear RF, Kelly PJ, Wright GM, Stalley P, McCaughan BC, Tattersall MH. Pulmonary metastasectomy for bone and soft tissue sarcoma in Australia: 114 patients from 1978 to 2008. Asia Pac J Clin Oncol. 2012;8:292-302.

19. Lin AY, Kotova S, Yanagawa J, Elbuluk O, Wang G, Kar N, et al. Risk stratification of patients undergoing pulmonary metastasectomy for soft tissue and bone sarcomas. J Thorac Cardiovasc Surg. 2015;149:85-92.

20. Harwood JL, Alexander JH, Mayerson JL, Scharschmidt TJ. Targeted chemotherapy in bone and soft-tissue sarcoma. Orthop Clin North Am. 2015; 46:587-608.

21. Mazumdar M, Glassman JR. Categorizing a prognostic variable: review of methods, code for easy implementation and applications to decision-making about cancer treatments. Stat Med. 2000;19:113-32.

22. Burnham KP, Anderson DR. Model Selection and Multimodel Inference. New York: Springer Verlag; 2002.

23. Ripley RT, Downey RJ. Pulmonary metastasectomy. J Surg Oncol. 2014;109: 42-6.

24. Rusch VW. Pulmonary metastasectomy. Current indications. Chest. 1995;107: $322 \mathrm{~s}-31 \mathrm{~s}$. 
25. Blackmon SH, Shah N, Roth JA, Correa AM, Vaporciyan AA, Rice DC, et al. Resection of pulmonary and extrapulmonary sarcomatous metastases is associated with long-term survival. Ann Thorac Surg. 2009;88:877-84.

26. Rehders A, Hosch SB, Scheunemann P, Stoecklein NH, Knoefel WT, Peiper M. Benefit of surgical treatment of lung metastasis in soft tissue sarcoma. Arch Surg. 2007; 142:70-5.

27. Mizuno T, Taniguchi T, Ishikawa Y, Kawaguchi K, Fukui T, Ishiguro F, et al. Pulmonary metastasectomy for osteogenic and soft tissue sarcoma: who really benefits from surgical treatment? Eur J Cardiothorac Surg. 2013;43:795-9.

28. Kim S, Ott HC, Wright CD, Wain JC, Morse C, Gaissert HA, et al. Pulmonary resection of metastatic sarcoma: prognostic factors associated with improved outcomes. Ann Thorac Surg. 2011;92:1780-6.

29. Rusch VW. Pulmonary metastasectomy: a moving target. J Thorac Oncol. 2010; 5:S130-1.

30. Stephens EH, Blackmon SH, Correa AM, Roth JA, Rice DC, Hofstetter W, et al. Progression after chemotherapy is a novel predictor of poor outcomes after pulmonary metastasectomy in sarcoma patients. J Am Coll Surg. 2011;212:821-6.

31. Cerfolio RJ, Bryant AS, McCarty TP, Minnich DJ. A prospective study to determine the incidence of non-imaged malignant pulmonary nodules in patients who undergo metastasectomy by thoracotomy with lung palpation. Ann Thorac Surg. 2011;91:1696-700.

32. McCormack PM, Ginsberg KB, Bains MS, Burt ME, Martini N, Rusch VW, et al. Accuracy of lung imaging in metastases with implications for the role of thoracoscopy. Ann Thorac Surg. 1993;56:863-5.

33. Treasure T, Fallowfield L, Lees B, Farewell V. Pulmonary metastasectomy in colorectal cancer: the PulMiCC trial. Thorax. 2012;67:185-7.

34. Teicher BA, Polley E, Kunkel M, Evans D, Silvers T, Delosh R, et al. Sarcoma cell line screen of oncology drugs and investigational agents identifies patterns associated with gene and microRNA Expression. Mol Cancer Ther. 2015;14:2452-62.

35. Yang J, Du X, Wang G, Sun Y, Chen K, Zhu X, et al. Mesenchymal to epithelial transition in sarcomas. Eur J Cancer. 2014;50:593-601.

Key Words: soft-tissue sarcoma, metastatic soft-tissue sarcoma, pulmonary metastasectomy, lung cancer surgery, metastases

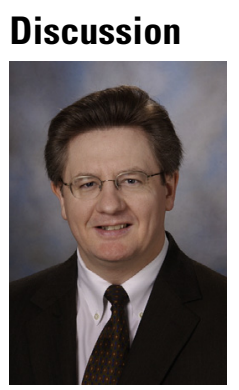

Dr G. Walsh (Houston, Tex). Congratulations, Neel, on a very nice presentation. I have been told that you are a general surgical resident who is doing research in thoracic surgery. I know that everyone in the room would share my sentiments that we hope you continue your interests in thoracic surgery, and maybe thoracic oncology, and I'm sure that there are some program director scouts out there right now who are taking note. Good work.

Dr Chudgar (New York, NY). Thank you.

Dr Walsh. This will be an often-cited manuscript, as it represents, at least in my review, the largest series of patients undergoing resection for soft-tissue sarcomas. It is an important retrospective analysis of a prospective database that Dr Murray Brennan had the wisdom to start in your institution back in 1982, and I have read recently that it has more than 10,000 surgical patients, and this is going to be another one of a number of very impactful reports that has come from your institution.

Pulmonary metastasectomies for sarcomas and other solid tumor metastasis is a pretty common referral and a common operation that most of us do, especially those of us who work in cancer centers. The patients do well postoperatively and often are followed by their medical oncologist. Although we will see them back for re-resection, as you pointed out, it's hard to get a real sense of the denominator of the problem, the number of people presenting to your institution, and the long-term outcomes. I think this is where your paper will be of such importance for us in helping us with patient selection and having the appropriate discussions with patients in our clinics.

As you know, these patients really have few options, and it is very difficult as a surgeon to observe a patient who has resectable disease. There has never been a randomized trial to help us answer the question: Are we really helping these patients or merely selecting patients with a more indolent biology to undergo an operation? Dr Tom Treasure has written a very nice systematic review of this in BMJ looking specifically at that and has started a European randomized study for colorectal patients to answer that question. I don't know if we could ever do that in North America or with sarcomas because it is such a heterogeneous group.

I have four questions, and I won't ask them all at one point. I am going to start with the hardest question, which is really the crux of the dilemma: your review demonstrates that the disease-free interval after resection was 6.8 months, yet one third of the patients survive 5 years. I want to know your thoughts since you are now the world's expert on resection of sarcomas. Is this surgical selection or biology with which we are dealing?

Dr Chudgar. Thank you for your comments, Dr Walsh, and thank you for reviewing our paper. I don't know that I am quite yet the world's expert, but I'll try.

You are correct, we did have a relatively short disease-free interval compared with the longer overall survival. This is a phenomenon that we have seen in other reviews as well; a paper from UCLA published within the last year, as well as, I believe, from the MD Anderson group. I think this does in part likely have to do with the patient's underlying tumor biology. This is a selected group of patients to begin with when we decided they were going to go to the operating room. These patients who recur after their pulmonary resection, I think that same disease biology that landed them into the resectability group to begin with will continue to have that association with their overall survival. So I do think there is a fair part of it that is our ability, with guidelines like these, to be able to select patients who have a more favorable tumor biology that will allow for a longer overall survival.

Dr Walsh. Do you think we ever could do a randomized study?

Dr Chudgar. I think you pointed to one of the main difficulties that we would be posed with in trying to perform one of these. Soft-tissue sarcomas are $1 \%$ of all cancers, so it is a much rarer disease. When we look at the trial going on 
in the United Kingdom led by Tom Treasure that you referred to, the PulMiCC trial, this is looking at colorectal cancer, which is a significantly greater incidence compared with sarcomas. When I was looking through some of their data, I believe it was going to take them approximately 15 years to accrue the number of patients that they felt was necessary for the trial. If we apply something like that to the case of soft-tissue sarcomas, I feel like we will run into the case of potentially not being able to meet the criteria and the power necessary to really find meaningful differences. It would provide the best level of evidence, absolutely, and I think what Dr Treasure is doing is certainly the right thing to get an answer, but I think it would be very difficult to do that for a disease like sarcoma.

Dr Walsh. So we can't do the randomized study. There were 200 patients in your study who had a diagnostic thoracotomy. Now, I don't know whether those patients just had too much disease, or could those patients be used perhaps for a propensity match to your 500 patients in your cohort who did undergo a pulmonary metastasectomy?

Dr Chudgar. That is a great question. The patients who were in that group of patients, about 200, those were patients who had the intent of going in for diagnosis early. Those were not just patients in whom the surgeon went in and realized that they were unresectable at the time. It was with a diagnostic intent. The idea of doing a propensitymatched analysis would definitely give us a higher level of evidence compared with what we have now. The one concern I have is with trying to match the two groups, a resected group versus a nonresected group, that the 2 groups might be different enough that it would be difficult to get the right power to keep our numbers up. A potential way to do this could be using something like inverse probability weighting. That is something that we could consider trying if we don't have enough power in doing a propensity match. I think that is a good way to try to at least compare the two groups in a more controlled fashion.

Dr Walsh. Your group had written a paper in the 1990s, the first look at this database, and had looked at the disease-free interval after patients who had had their second pulmonary metastasectomy. Do you have the disease-free interval for that group of patients, the third that went back and were re-resected?

Dr Chudgar. That is the current thing that we are now looking into. We want to look at the cohort of patients, the $29 \%$, who had a repeat resection following the initial data that we presented here. We don't quite have the exact disease-free interval yet. When we look at all of the patients who have a pulmonary recurrence after an initial metastasectomy, we do note that in the patients who undergo a next operation, those patients have a longer disease-free interval from the first resection to their upcoming recurrence. I would hypothesize that this group at their second metastasectomy would have a longer disease-free interval. These data should be hopefully on the way soon. I think shortly that I might be able to provide a better answer than that.

Dr Walsh. The last question is a practical one. You go back to your clinic this Friday and you see a patient who has a high-grade tumor, the original tumor was $11 \mathrm{~cm}$ from their extremity resected 6 months ago, and they have 4 lesions in the lung. What are you going to do for that patient who is looking at you right now with resectable disease, and have you thought of using this very powerful database to do, say, a nomogram to help surgeons have that sort of difficult conversation with a patient?

Dr Chudgar. A patient presenting with that many negative factors, I think based on the data that we have presented today, would be probably on the side of not undergoing a pulmonary metastasectomy. That being said, I think every patient has to be viewed individually, and a nomogram would be something that would be much more helpful and something that we are working on with our biostatisticians so that we can kind of get a collective predictive value of all of the different disease factors that a patient will enter your office with so that we can kind of more accurately predict where their survival curve might exactly lie. I think the other important part, though, when we are deciding on whether or not to operate on these complex patients is to make sure we institute some sort of multidisciplinary meeting or group that will look at a patient from the surgeon's aspect and the medical oncologist's aspect. These are often difficult patients to treat and it helps to kind of have all hands on board. That is something that we do at our institution.

Dr Walsh. Thank you.

Dr M. Cypel (Toronto, Ontario, Canada). This is a very nice study. Congratulations. This is very helpful information, especially the subtypes of soft-tissue sarcoma and the prognostic factors related to that.

Have you tried to combine some categories of high risk versus low risk, as the registry initially stratified, in groups, which could help?

Dr Chudgar. Yes, we want to. We are working on that.

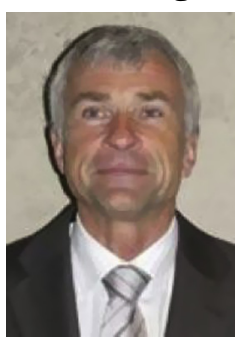
Dr W. Klepetko (Vienna, Austria). I very much enjoyed this study.

In your data you just restricted to patients with intrapulmonary metastases. Now, the reality is that not infrequently we see patients with one solitary metastasis involving adjacent structures needing an extended resection. Were these patients completely excluded from this study or is your policy not to operate on those patients?

Dr Chudgar. There was a subset of patients who did have extrapulmonary but within-the-chest disease, whether it was pleural disease or disease at the diaphragm. So we did consider those patients within our study. They were not excluded. 


\section{Primary Histology}

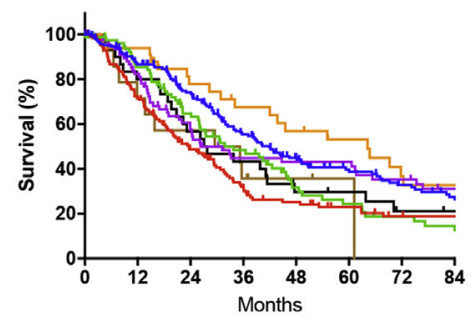

- LMS

- PS/MFH

- Synovial

- Other

- Fibrosarcoma

- Liposarcoma

- MPNST

$p=0.001$

\begin{tabular}{|c|c|c|c|c|c|c|c|c|c|}
\hline Histology & \multicolumn{8}{|c|}{ Number at Risk (95\% Cl) } & Median \\
\hline LMS & 169 & $\begin{array}{c}139 \\
(0.81, \\
0.92)\end{array}$ & $\begin{array}{c}112 \\
\left(\begin{array}{ccc}112,0 \\
811)\end{array}\right.\end{array}$ & $\begin{array}{c}77 \\
(0.48, \\
0.64)\end{array}$ & $\begin{array}{c}55 \\
(0.37 \\
0.54)\end{array}$ & $\begin{array}{c}41 \\
(0.32 \\
0.49)\end{array}$ & $\begin{array}{c}32 \\
(0.25 \\
0.42)\end{array}$ & $\begin{array}{c}25 \\
(0.20,0) \\
0.377)\end{array}$ & 42.0 \\
\hline PSMFH & 130 & $\begin{array}{c}91 \\
0.064 \\
0.80)\end{array}$ & $\begin{array}{c}56 \\
(0.41 \\
0.58)\end{array}$ & $\begin{array}{c}34 \\
(025) \\
0.42)\end{array}$ & $\begin{array}{c}24 \\
(0.18 \\
0.35)\end{array}$ & $\begin{array}{c}17 \\
(0.16 \\
0.32)\end{array}$ & $\begin{array}{c}11 \\
\left(\begin{array}{l}11.11 \\
0.27)\end{array}\right.\end{array}$ & $\begin{array}{c}10 \\
0.11 \\
0.277\end{array}$ & 23.6 \\
\hline Synovial & 81 & $\begin{array}{c}64 \\
(0.78, \\
0.94)\end{array}$ & $\begin{array}{c}44, \\
(0.55, \\
0.77)\end{array}$ & $\begin{array}{c}31 \\
(0.38, \\
0.62)\end{array}$ & $\begin{array}{c}18 \\
(0.22, \\
0.45)\end{array}$ & $\begin{array}{c}13 \\
(0.16, \\
0.38)\end{array}$ & $\begin{array}{c}9 \\
\left(\begin{array}{l}0.11 \\
0.32)\end{array}\right.\end{array}$ & $\begin{array}{c}7 \\
(0.8, \\
0.28)\end{array}$ & 32.3 \\
\hline Other & 81 & $\begin{array}{c}58 \\
(0.74 \\
0.92)\end{array}$ & $\begin{array}{c}38 \\
0.47 \\
0.70 j\end{array}$ & $\begin{array}{c}26 \\
0.34 \\
0.59)\end{array}$ & $\begin{array}{c}25 \\
(0.33 \\
0.577\end{array}$ & $\begin{array}{c}22 \\
(0.33 \\
0.57)\end{array}$ & $\begin{array}{c}18 \\
(0.25 \\
0.50)\end{array}$ & $\begin{array}{c}14 \\
(0.21 . \\
0.46)\end{array}$ & 26.7 \\
\hline Fibrosarcoma & 33 & $\begin{array}{c}31 \\
(0.86 \\
1.00)\end{array}$ & $\begin{array}{c}23 \\
(0.65, \\
0.94)\end{array}$ & $\begin{array}{c}19 \\
(0.53 \\
0.86)\end{array}$ & $\begin{array}{c}16 \\
(0.42) \\
0.78)\end{array}$ & $\begin{array}{c}13 \\
(0.38 \\
0.75)\end{array}$ & $\begin{array}{c}9 \\
(0.22, \\
0.60) \\
0.5\end{array}$ & $\begin{array}{c}8 \\
(0.19 \\
0.57) \\
0\end{array}$ & 65.2 \\
\hline Liposarcoma & 30 & $\begin{array}{c}24 \\
(0.67 \\
0.96 ;\end{array}$ & $\begin{array}{c}17 \\
(0.41 \\
0.77)\end{array}$ & $\begin{array}{c}13 \\
(0.29 \\
0.65)\end{array}$ & $\begin{array}{c}8 \\
(0.17 \\
0.52)\end{array}$ & $\begin{array}{c}7 \\
0.17 \\
0.52 j\end{array}$ & $\begin{array}{c}4 \\
(0.10 \\
0.44) \\
0.44\end{array}$ & $\begin{array}{c}3 \\
(0.10 \\
0.44)\end{array}$ & 27.9 \\
\hline MPNST & 15 & $\begin{array}{c}10 \\
(10.51 ; \\
0.999)\end{array}$ & $\begin{array}{c}8 \\
(0.36, \\
0.90)\end{array}$ & $\begin{array}{c}5 \\
0.18 \\
0.72) \\
0.72\end{array}$ & $\begin{array}{c}2 \\
\left(\begin{array}{c}2.18 \\
0.72)\end{array}\right.\end{array}$ & $\begin{array}{c}1 \\
\left(\begin{array}{c}1.18 \\
0.72)\end{array}\right. \\
0.72\end{array}$ & 0 & 0 & 32.9 \\
\hline
\end{tabular}

A

\section{Type of Surgery}
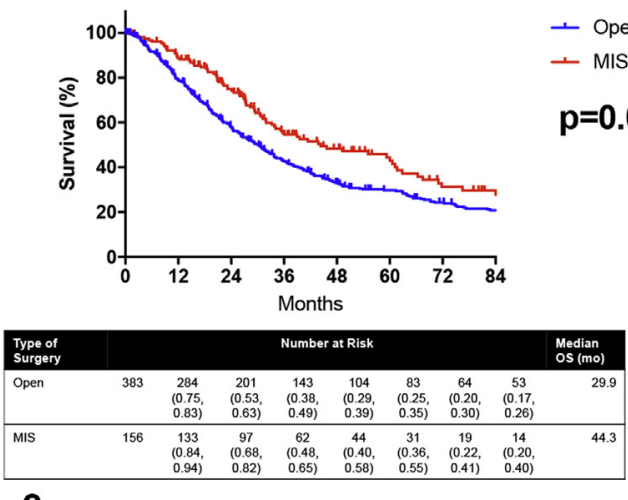

c

FIGURE E1. Kaplan-Meier curves of overall survival by (A) primary histology, (B) disease-free interval, and (C) type of surgery. LMS, Leiomyosarcoma; $P S$, pleomorphic sarcoma; $M F H$, malignant fibrous histiocytoma; $M P N S T$, malignant peripheral nerve sheath tumor; $C I$, confidence interval; $O S$, overall survival; $D F I$, disease-free interval; $M I S$, minimally invasive surgery.

TABLE E1. Interaction analyses for overall survival

\begin{tabular}{lc}
\hline \multicolumn{1}{c}{ Interaction } & $\begin{array}{c}\boldsymbol{P} \text { value for } \\
\text { interaction }\end{array}$ \\
\hline Size of primary vs number of metastases & .286 \\
Grade of primary vs number of metastases & .842 \\
Interval to first metastasis vs number of metastases & .611 \\
Size of primary vs grade of primary & .504 \\
Size of primary vs interval to first metastasis & .998 \\
Interval of first metastasis vs grade of primary & .823 \\
\hline
\end{tabular}

\section{Disease-Free Interval}
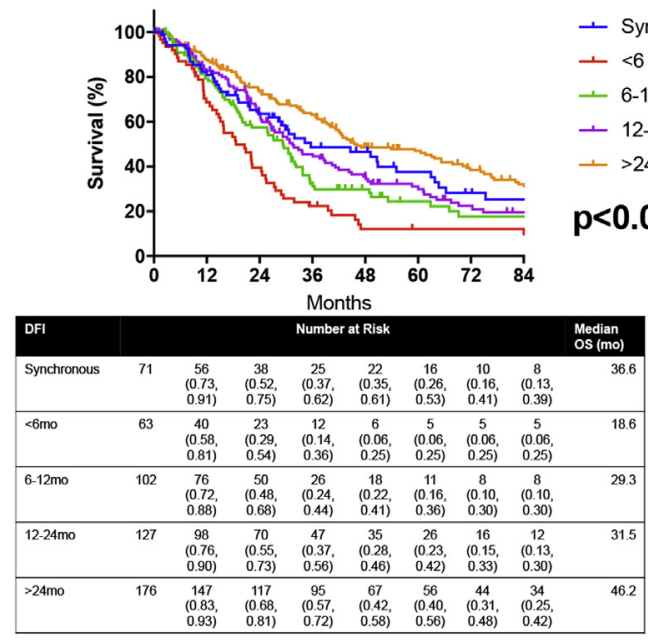

B
+ Synchronous

$+<6$ months

- 6-12 months

- 12-24 months

- > 24 months

$p<0.001$ 